\title{
Free anteromedial thigh perforator flap: Complementing and completing the anterolateral thigh flap
}

\author{
Dushyant Jaiswal, Amol Ghalme1, Prabha Yadav, Vinaykant Shankhdhar, Akshay Deshpande ${ }^{1}$ \\ Plastic and Reconstructive Surgery Services, Tata Memorial Centre, ${ }^{1}$ Tata Memorial Centre, Mumbai, Maharashtra, India
}

Address for correspondence: Dr. Amol Ghalme, Vedant Hospital, Shreehari Kute Marg, Nashik - 422 002, Maharashtra, India.

E-mail: amolghalme@gmail.com

\section{ABSTRACT}

Objective: Theobjective of this study was to determine the indications, utility, advantages and surgical approach for the anteromedial thigh (AMT) flap. Materials and Methods: We reviewed the records of the patients in whom the AMT flap was used for head and neck reconstruction. We use an anterior approach to harvest the anterolateral thigh (ALT) flap with a non-committal straight line incision. This preserves both ALT and AMT flap territories intact, and further decision is based on the intraoperative anatomy of perforator and pedicle. The ALT flap was usually used as the first choice when available and suitable. Results: Free AMT skin flaps were harvested in 24 patients. All flaps were used for the head and neck reconstruction. Two flaps had marginal flap necrosis. One flap was lost due to venous thrombosis. Discussion: The thigh is an excellent donor site as it has large available skin territory, expendable lateral circumflex femoral artery system and low donorsite morbidity. The ALT flap is the most commonly used flap for reconstruction of soft-tissue defects. However, it is characterised by variable vascular pedicle and perforator anatomy. The AMT flap is an excellent alternative when the ALT flap is not available due to variable perforator anatomy, injury to perforator, when an intermediate thickness is needed between distal and proximal thigh or a chimeric flap is needed. Conclusion: The AMT flap offers all the advantages of the ALT flap without increasing donor-site morbidity. The anterior non-committal approach keeps both the ALT and the AMT flap options viable.

\section{KEY WORDS}

Anteromedial thigh perforator flap; chimeric flaps; freestyle perforator flap

\section{INTRODUCTION}

n 1984, Song et al. ${ }^{[1]}$ first described the anterolateral thigh (ALT) flap based on perforators of descending branch of the lateral circumflex femoral artery (LCFA).

\begin{tabular}{|l|l|}
\hline \multicolumn{2}{|c|}{ Access this article online } \\
\hline Quick Response Code: & Website: \\
\hline & www.ijps.org \\
\cline { 2 - 2 } & \\
\hline
\end{tabular}

In the same year, they have also first reported the anteromedial thigh (AMT) flap. ${ }^{[1]}$

This is an open access article distributed under the terms of the Creative Commons Attribution-NonCommercial-ShareAlike 3.0 License, which allows others to remix, tweak, and build upon the work non-commercially, as long as the author is credited and the new creations are licensed under the identical terms.

For reprints contact: reprints@medknow.com

How to cite this article: Jaiswal D, Ghalme A, Yadav P, Shankhdhar V, Deshpande A. Free anteromedial thigh perforator flap: Complementing and completing the anterolateral thigh flap. Indian J Plast Surg 2017;50:16-20. 
At present, the ALT flap is a workhorse flap for soft-tissue reconstruction of regional as well as distant defects. We analysed the departmental database and hospital electronic medical records with the purpose of reviewing the AMT flap in terms of its indications, vascular anatomy and surgical approach.

\section{MATERIALS AND METHODS}

Among the 2000 reviewed free flaps operated at a tertiary care centre for cancer management from January 2012 to December 2015, 810 patients of free thigh perforator flaps for reconstruction of defects in the head and neck region were reviewed. Of these, 782 were free ALT flaps, 20 were free AMT flaps, 4 were free tensor fasciae latae (TFL) flaps and 4 were chimeric AMT-ALT flaps. Thus, a total of 24 AMT skin flaps were harvested which are included for further analysis. A retrospective review of database is performed with respect to demographics, reasons for choosing AMT, average size of flap, modifications, complications and success rates.

\section{Operative technique}

The axis of ALT flap is marked by a line joining the anterior superior iliac spine (ASIS) and supero-lateral border of the patella on the thigh. The axis of AMT flap is marked by another line joining the ASIS and superomedial border of patella. A hand-held audio Doppler $8 \mathrm{MHz}$ was done to scan for perforators pre-operatively in the ALT and AMT flap territory around the midpoint of two axes lines; no other imaging modality was employed for logistical reasons.

The anterior sub-fascial approach was used for flap harvest. We use and propose a non-committal straight line incision at the junction of ALT and AMT flap territory for the harvest of a thigh flap [Figure 1]. The incision is deepened to deep fascia of the thigh. The ALT flap is our first choice. If a suitable ALT perforator is not identified, the incision can be extended proximally or distally to increase the area of search; this most often yields a perforator. Simultaneously or in sequence, a search for AMT perforator is made on the medial side of flap through the same incision. Once the sizable perforator is located, a free-style skin flap is harvested from the antero-medial thigh. The perforator is dissected either through the muscle or through its course within a septum to the source vessel until the adequate pedicle length and size of the vessels for a safe anastomosis are achieved. The free-style perforator flap dissection is then

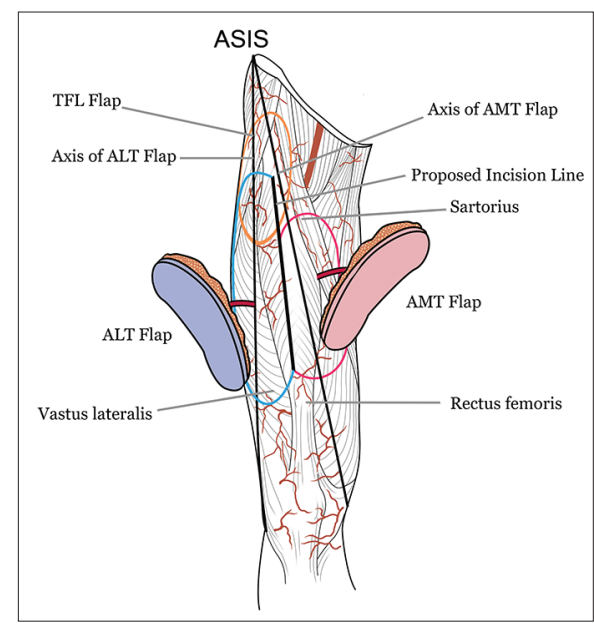

Figure 1: Proposed non-committal straight line anterior incision, axis of anterolateral thigh flap - anterior superior iliac spine to lateral aspect of patella, axis of anteromedial thigh flap and anterior superior iliac spine to medial aspect of patella

completed, and the flap is transferred into the defect in usual fashion [Figure 2].

\section{RESULTS}

In all 24 patients, AMT flaps were used as free flaps for soft-tissue reconstruction of post-cancer excision defects of the head and neck region. Seventeen patients were male and seven were female. Average flap size was $12-20 \mathrm{~cm} \times 6-7.5 \mathrm{~cm}$. The reasons for choosing the AMT flap were as follows: there was no sizeable/suitable ALT perforator in 19 patients. There was an injury to ALT perforator in one patient. Four patients had large composite multiplanar defects following the resection of head and neck tumour. They were reconstructed using a chimeric-free ALT plus AMT flaps [Figure 3].

Fifteen flaps were harvested on a single perforator. There were two septocutaneous perforators in seven flaps and three septocutaneous perforators in two flaps. Of the 24 flaps, 18 had septocutaneous perforators while remaining 6 had single perforator with musculocutaneous course.

The donor vessel dissection was done until the adequate pedicle length and size for safe anastomosis were achieved. The donor vessels were LCFA in 14 patients, its descending branch in 6 , deep femoral artery in 2 and superficial femoral artery in 2 patients.

Donor site needed skin grafting in three patients of chimeric ALT with AMT flap harvest; remaining donor sites were primarily closed [Figure 4]. 


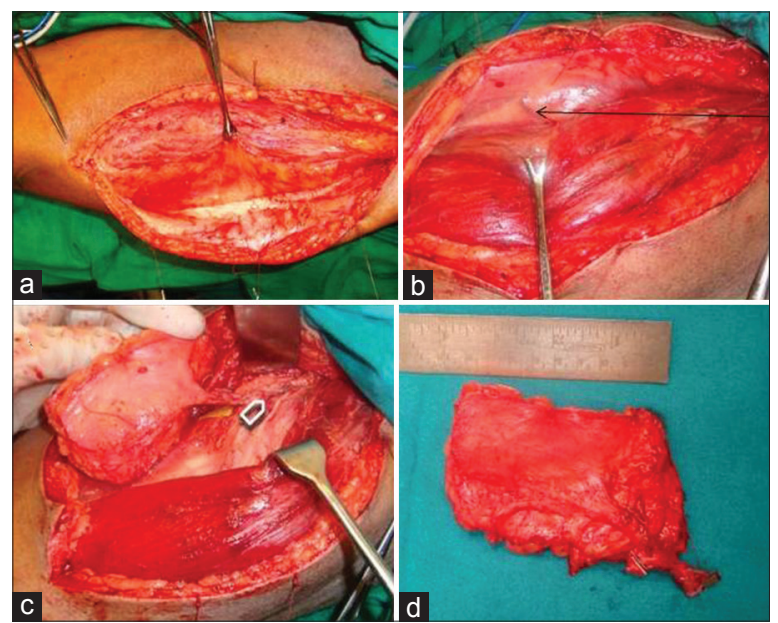

Figure 2: (a) Perforator for anterolateral thigh flap was absent. (b) Septocutaneous perforator for anteromedial thigh flap (arrow) was identified on medial flap. (c) Perforator to source vessel - lateral circumflex femoral artery (arrowhead) dissection was done. (d) Anteromedial thigh flap after completion of harvest
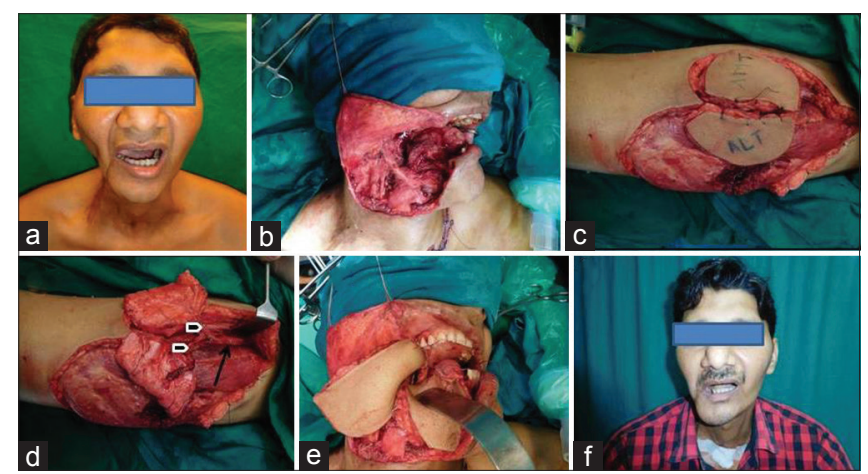

Figure 3: (a) Pre-operative image of a patient of recurrent cancer buccal mucosa and cancer tongue synchronous primary lesions. (b) Intraoperative image depicting the right buccal mucosa and right hemiglossectomy defect after resection for both the lesions. (c and d) Chimeric anterolateral thigh and anteromedial thigh flap based on two separate perforators (arrowheads) from single mother vessel, lateral circumflex femoral artery (arrow). (e) Separate insetting of two flaps. (f) Post-operative image

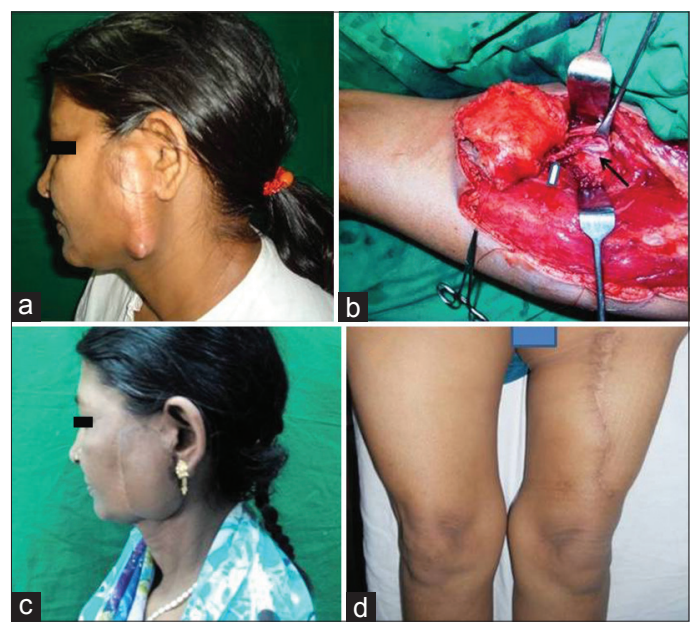

Figure 4: (a) Pre-operative image of the patient of recurrent carcinoma of parotid gland. (b) Intra-operative image showing perforator (white arrow) arising from superficial femoral vessels (black arrow). (c) 2-year post-operative

image - well-settled flap. (d) 2-year post-operative image - donor-site scar
Two patients had re-exploration for venous congestion. Of the two, one flap was salvaged. One flap was lost secondary to orocutaneous fistula. Orocutaneous fistula was a consequence of dehiscence of the flap inset secondary to flap edge necrosis. One patient with chimeric flap developed partial necrosis of flap which was managed conservatively by the secondary suturing.

The overall success rate was $95.83 \%$ (23 out of 24 ).

\section{DISCUSSION}

At present, the goal of reconstruction is not only to achieve optimal functional and aesthetic outcome but also to minimise the donor-site morbidity. Therefore, the selection of the 'right' flap is imperative because an inappropriate choice may not achieve the desired result, no matter how meticulous the surgical execution. ${ }^{[2]}$

The introduction of the perforator flap concept and free-style perforator flap technique as described by Wei and Mardini[i] has actually resulted into achieve this goal to a certain extent. The thigh is one such donor site which provides ample of tissue bulk and skin paddle for the reconstruction of soft-tissue defects. The ALT flap is workhorse flap for soft-tissue defects by virtue of its versatility.

However, its main limitation is variable perforator and pedicle anatomy. In $2 \%$ of patients, ALT perforator may not be suitable for flap harvest. ${ }^{[4]}$ Kimata et al. ${ }^{[5]}$ demonstrated in their initial report that there was no perforator found in 4 of the 74 patients (5.4\%). However, the percentage of having no perforator is stated to be less $\left(0.89 \%[6 / 672],{ }^{[6]} 1.37 \%[6 / 439],{ }^{[7]} 1.45 \%[1 / 69]^{[8]}\right.$ and $\left.1.8 \%[3 / 168]^{\mid 9]}\right)$ in various other reports. Occasionally, there can be injury to ALT perforator during dissection, which renders the inability to harvest the ALT flap.

Hence, it is essential to have an alternative flap as a backup plan for successful reconstruction. Simply turning to the other side of the thigh or another donor site will increase the morbidity caused by donor sites.

The perforator flap of the adjacent region becomes the first alternative choice because it provides the same quality and function as the initially planned. The perforasome theory by Saint-Cyr supports the use of the AMT flap when the ALT flap is not available. ${ }^{[10]}$ The AMT flap has relatively hairless skin compared with the skin of the ALT 
flap. The thickness of the thigh is not the same in all parts. The proximal thigh is usually much thicker as compared to rest of the thigh including AMT. In a scenario where an AMT perforator is suitable and thickness matches that of the defect compared to a proximal ALT/TFL perforator with much more thickness or a distal ALT perforator in a thinner part of the thigh, we prefer to harvest the AMT as a matter of choice. However, the AMT flap is more challenging in the sense that perforators have multiple variations and may lead to various source vessels. ${ }^{[11,12]}$ Despite the anatomical variations, the perforator can be visually identified first followed by elevation of the flap making this a reliable alternative. ${ }^{[12,13]}$

The perforator of the AMT flap could arise anywhere from the femoral artery, the LCFA, the medial or lateral descending branch of the LCFA, the innominate branch or from a minor muscle branch to the rectus femoris muscle. ${ }^{[11,12,14,15]}$

If there is no suitable perforator in the ALT flap region, the TFL flap based on perforator leading to the transverse branch can also be planned. ${ }^{[16,17]}$ However, the initial design of the ALT flap frequently involves this region not sparing enough skin flaps to be used. Furthermore, the pedicle length TFL flap is short. The AMT flap is thinner and more pliable than the TFL flap, and these characteristics are specifically important in the reconstruction of the head and neck region. ${ }^{[18]}$

Large defects of the head and neck region are challenging to reconstruct as there may be a three-dimensional requirement of both the volume and the multiple surfaces for oral lining and external skin. ${ }^{[19]}$ In these situations, the chimeric ALT flap is particularly versatile. As the LCFA gives of the various branches, multiple components can be harvested based on the main pedicle. ${ }^{[20]}$

Chimeric flaps (ALT with AMT) are used with each paddle based on separate perforators. ${ }^{[21]}$ This versatility facilitates in setting of the flap to the complex three-dimensional defects. It allows the provision of multiple tissue components as a single yet comprehensive unit. Wei et al. ${ }^{[22]}$ have elegantly shown to be an 'ideal' attribute of the thigh region.

If a single 'mother' vessel serves all the independent portions of a chosen combined free flap, then only a single recipient site may be required for revascularisation. This is most advantageous if there is a paucity of recipient vessels, such as after bilateral radical neck dissection, post-radiation neck, recurrent lesions and a single-vessel lower extremity. ${ }^{[23]}$

\section{CONCLUSION}

The AMT flap offers all the advantages of the ALT flap without increasing the donor sites. We suggest a non-committal straight line anterior approach to harvest a thigh flap. The AMT flap is a good alternative to the ALT flap when suitable ALT perforator is not present or injured. The chimeric AMT flap along with the ALT flap is one of the most suitable options to reconstruct large complex soft defects of the head and neck region.

\section{Acknowledgement}

The authors would like to thank Mr. Manish Mistry and Mrs. Pallavi Mistry for their contribution in illustration of Figure 1.

\section{Declaration of patient consent}

The authors certify that they have obtained all appropriate patient consent forms. In the form the patient(s) has/have given his/her/their consent for his/her/their images and other clinical information to be reported in the journal. The patients understand that their names and initials will not be published and due efforts will be made to conceal their identity, but anonymity cannot be guaranteed.

\section{Financial support and sponsorship}

Nil.

\section{Conflicts of interest}

There are no conflicts of interest.

\section{REFERENCES}

1. Song YG, Chen GZ, Song YL. The free thigh flap: A new free flap concept based on the septocutaneous artery. $\mathrm{Br} J$ Plast Surg 1984;37:149-59.

2. Hallock GG. Flap selection. In: Wei FC, Mardini S, editors. Flaps and Reconstructive Surgery. China. Saunders Elsevier; 2009. p. 17.

3. Wei FC, Mardini S. Free-style free flaps. Plast Reconstr Surg 2004;114:910-6.

4. Mardini S, Lin LC, Morgan SL, Salgado CJ, Wei FC. Anterolateral thigh flap. In: Wei FC, Mardini S, editors. Flaps and Reconstructive Surgery. China aunders Elsevier; 2009. p. 542.

5. Kimata Y, Uchiyama K, Ebihara S, Nakatsuka T, Harii K. Anatomic variations and technical problems of the anterolateral thigh flap: A report of 74 cases. Plast Reconstr Surg 1998;102:1517-23.

6. Wei FC, Jain V, Celik N, Chen HC, Chuang DC, Lin CH. Have we found an ideal soft-tissue flap? An experience with 672 anterolateral thigh flaps. Plast Reconstr Surg 2002;109:2219-26.

7. Celik N, Wei FC, Lin CH, Cheng MH, Chen HC, Jeng SF, et al. 
Technique and strategy in anterolateral thigh perforator flap surgery, based on an analysis of 15 complete and partial failures in 439 cases. Plast Reconstr Surg 2002;109:2211-6.

8. Hong JP, Kim EK. Sole reconstruction using anterolateral thigh perforator free flaps. Plast Reconstr Surg 2007;119:186-93.

9. Luo S, Raffoul W, Luo J, Luo L, Gao J, Chen L, et al. Anterolateral thigh flap: A review of 168 cases. Microsurgery 1999;19:232-8.

10. Saint-Cyr M, Wong C, Schaverien M, Mojallal A, Rohrich RJ. The perforasome theory: Vascular anatomy and clinical implications. Plast Reconstr Surg 2009;124:1529-44.

11. Schoeller T, Huemer GM, Shafighi M, Gurunluoglu R, Wechselberger G, Piza-Katzer H. Free anteromedial thigh flap: Clinical application and review of literature. Microsurgery 2004;24:43-8.

12. Riva FM, Tan NC, Liu KW, Hsieh CH, Jeng SF. Anteromedial thigh perforator free flap: Report of 41 consecutive flaps and donor-site morbidity evaluation. J Plast Reconstr Aesthet Surg 2013;66:1405-14.

13. Hong JP, Kim EK, Kim H, Shin HW, Hwang CH, Lee MY. Alternative regional flaps when anterolateral thigh flap perforator is not feasible. $\mathrm{J}$ Hand Microsurg 2010;2:51-7.

14. Koshima I, Yamamoto H, Moriguchi T, Orita Y. Extended anterior thigh flaps for repair of massive cervical defects involving pharyngoesophagus and skin: An introduction to the "mosaic" flap principle. Ann Plast Surg 1994;32:321-7.

15. Chen HC, Tang YB. Anterolateral thigh flap: An ideal soft tissue flap. Clin Plast Surg 2003;30:383-401.
16. Koshima I, Urushibara K, Inagawa K, Moriguchi T. Free tensor fasciae latae perforator flap for the reconstruction of defects in the extremities. Plast Reconstr Surg 2001;107:1759-65.

17. Zhou G, Qiao Q, Chen GY, Ling YC, Swift R. Clinical experience and surgical anatomy of 32 free anterolateral thigh flap transplantations. Br J Plast Surg 1991;44:91-6.

18. Hsieh $\mathrm{CH}$, Yang JC, Chen CC, Kuo YR, Jeng SF. Alternative reconstructive choices for anterolateral thigh flap dissection in cases in which no sizable skin perforator is available. Head Neck 2009;31:571-5.

19. Chana JS, Odili J. Perforator flaps in head and neck reconstruction. Semin Plast Surg 2010;24:237-54.

20. Huang WC, Chen HC, Jain V, Kilda M, Lin YD, Cheng $M H$, et al. Reconstruction of through-and-through cheek defects involving the oral commissure, using chimeric flaps from the thigh lateral femoral circumflex system. Plast Reconstr Surg 2002;109:433-41.

21. Koshima I, Yamamoto H, Hosoda M, Moriguchi T, Orita $Y$, Nagayama $\mathrm{H}$. Free combined composite flaps using the lateral circumflex femoral system for repair of massive defects of the head and neck regions: An introduction to the chimeric flap principle. Plast Reconstr Surg 1993;92:411-20.

22. Wei FC, Celik N, Jeng SF. Application of "simplified nomenclature for compound flaps" to the anterolateral thigh flap. Plast Reconstr Surg 2005;115:1051-5.

23. Mardini S, Tsai FC, Wei FC. The thigh as a model for free style free flaps. Clin Plast Surg 2003;30:473-80. 